\title{
ANÁLISE MICROBIOLÓGICA DE SALADAS DE FRUTAS COMERCIALIZADAS NO MUNICÍPIO DE POUSO ALEGRE - MG
}

\author{
MICROBIOLOGICAL ANALYSIS OF \\ COMMERCIALIZED FRUIT SALADS IN THE \\ MUNICIPALITY OF POUSO ALEGRE - MG
}

\author{
Rute Quéren da Cunha \\ rute.cunha.rc@gmail.com \\ Profa. Orientadora Esp. Gabriela Frazão Reimberg Silva \\ gabriela.alimentha@gmail.com \\ Prof. Coorientador Me. Luiz Francisley de Paiva \\ francisleybiologo@yahoo.com.br
}

Universidade do Vale do Sapucaí - UNIVÁS

RESUMO: O presente estudo teve como objetivo avaliar a qualidade microbiológica de saladas de frutas comercializadas em Pouso Alegre - MG, verificando se estas atendem aos padrões microbiológicos para enumeração de coliformes totais e coliformes termotolerantes estabelecidos pela RDC № 12 de 2001. As amostras pertenciam a vinte estabelecimentos comerciais diferentes e foram adquiridas no período de agosto a setembro de 2019 no comércio local. As amostras foram diluídas 1/10, 1/100 e 1/1000. Uma alíquota de $1 \mathrm{~mL}$ de cada diluição foi inoculada pela técnica pour plate utilizando o meio Agar Vermelho Violeta Bile. As placas foram incubadas em temperatura de 35ㄷ $\mathrm{C}$ por $24-48$ horas e após esse período as colônias, quando presentes, foram contadas e identificadas. Das 20 amostras analisadas em nenhuma houve crescimento de coliforme termotolerantes sendo este resultado satisfatório, porém, em $75 \%$ das amostras houve presença de coliformes totais. Apesar de em todas as amostras encontrarem-se dentro dos padrões microbiológicos vigentes para coliformes termotolerantes, os elevados valores encontrados de coliformes totais evidenciam que o produto pode fornecer risco ao consumidor.

Palavras-chave: Alimentos preparados. Coliformes. Manipulação de alimentos.

ABSTRACT: The present study aimed to evaluate the microbiological quality of fruit salads sold in Pouso Alegre - MG, verifying if they meet the microbiological standards for enumeration of total coliforms and thermotolerant coliforms established by RDC No. 12 of 2001.The samples belonged to twenty different commercial establishments and were acquired from August to September 2019 in local trade. The samples were diluted 1/10,1/100 and 1/1000. A $1 \mathrm{~mL}$ aliquot of each dilution was inoculated using the pour plate technique using Agar Red Violet Bile. The plates were incubated at a temperature of $35^{\circ} \mathrm{C}$ for 24 48 hours and after this period the colonies when present, were counted and identified. Of the 20 samples analyzed in none, there was growth of thermotolerant coliform, this result being satisfactory, however, in $75 \%$ of the samples there was the presence of total coliforms. Although in all samples they are within the current microbiological 
standards for thermotolerant coliforms, the high values found for total coliforms show that the product can provide risk to the consumer.

Keywords: Prepared Foods. Coliforms. Food Handling.

\section{INTRODUÇÃO}

A sociedade atual tem buscado, cada vez mais, hábitos de vida saudáveis e naturais, o que gera um aumento do consumo de frutas e hortaliças em todo o mundo. O consumidor tem procurado por produtos prontos para o consumo ou que demandam pouca ou nenhuma ação para serem preparados e consumidos com segurança, ou seja, proporcionando mais praticidade e comodidade na compra e consumo de frutas e hortaliças. (OLIVEIRA; SANTOS, 2015).

A salada de frutas é um alimento minimamente processado, que vem sendo largamente distribuído e incluído na dieta de indivíduos que buscam manter uma alimentação saudável. O processamento ao qual esse produto é submetido não acarreta alterações significativas nas características nutricionais desse alimento, são práticos e apresentam um produto semelhante ao alimento fresco (SILVA et al., 2018).

Por serem fontes potenciais de microrganismos patógenos, (SANTOS et al., 2010) a segurança e a qualidade microbiológica de frutas minimamente processadas, nas últimas duas décadas têm sido motivo de preocupação, pela sua maior associação com surtos de doenças transmitidas por alimentos, (MAISTRO et al., 2012) ,dentre outros fatores, isso deve ao fato de que o corte danifica as barreiras naturais de proteção do produto, liberando nutrientes, 0 que favorece 0 desenvolvimento de microrganismos (JEDDI et al., 2014), além disso, o elevado manuseio a que são submetidos também afetam a segurança microbiológica desses produtos (OLIVEIRA; SANTOS, 2015).

Dada a importância do monitoramento das condições higiênico sanitárias, vários autores já investigaram o grupo de coliformes como indicador higiênico sanitário em diversos alimentos. Visto que, a salada de fruta é um alimento amplamente consumido, podendo ser facilmente contaminado durante seu preparo, apresentando assim um risco microbiológico aos consumidores, o presente trabalho teve como objetivo avaliar a qualidade microbiológica de saladas de frutas comercializadas no município de Pouso Alegre - MG, verificando se estas atendem aos padrões microbiológicos estabelecidos pela RDC 12 de 02 de janeiro de 2001, da Agência Nacional de Vigilância Sanitária (BRASIL, 2001), pois espera-se que 0 processamento mínimo ofereça aos consumidores alimentos seguros do ponto de vista microbiológico. 
METODOLOGIA

\section{Amostras}

Foram adquiridas vinte amostras em vinte diferentes estabelecimentos no período de 27 de agosto a 24 de setembro de 2019 no comércio da cidade de Pouso Alegre - MG. As saladas de frutas foram preparadas no momento da compra. Em embalagens originais lacradas, as amostras foram transportadas para 0 Laboratório de Pesquisas Básicas em uma caixa isotérmica contendo gelo e a realização dos testes não excedeu 24 horas após a aquisição.

\section{Análises microbiológicas}

Para a análise de coliformes totais, termotolerantes e Escherichia coli foi utilizado o método de plaqueamento em Agar Vermelho Violeta Bile (VRB) de acordo com o método da American Public Health Association descrita no Compendium of methods for the microbiological examination of foods (APHA, 2015).

Para realização das análises microbiológicas, foram preparadas diluições seriadas decimais até $10^{-3}$. Em um Becker limpo e estéril foram pesadas assepticamente $25 \mathrm{~g}$ da amostra que em seguida foram transferidas para um erlenmeyer com $225 \mathrm{~mL}$ de peptonada $\left(\mathrm{H}_{2} \mathrm{O}_{\mathrm{p}}\right) \quad 0,1 \%$. As amostras foram homogeneizadas durante 5 minutos. A partir desta solução, realizou- se diluições seriadas decimais de 1/10 (v/v) onde uma alíquota de $1 \mathrm{~mL}$ foi transferido para tubo contendo $9 \mathrm{~mL}$ de $\mathrm{H}_{2} \mathrm{O}_{\mathrm{p}}$ 0,1\%, assim sendo, obteve-se uma diluição $10^{-2}$ e posteriormente $10^{-3}$.

Após homogeneização, $1 \mathrm{~mL}$ de cada diluição foram dispensadas no centro das respectivas placas de Petri estéril $20 \mathrm{x}$ $100 \mathrm{~mm}$. Em seguida foi adicionado em cada placa aproximadamente $25 \mathrm{~mL}$ do meio Agar Vermelho Violeta Bile previamente fundido à placa contendo a amostra. As placas foram fechadas imediatamente e foram homogeneizados com movimentos de "8". Após a solidificação do meio, foram adicionados novamente sobre as mesmas placas, uma sobrecamada de aproximadamente 5 - 8 $\mathrm{mL}$ do meio Agar Vermelho Violeta Bile.

As placas foram identificadas $\mathrm{e}$ incubadas a $24-48$ horas a $35^{\circ} \mathrm{C} \pm 2^{\circ} \mathrm{C}$. Após esse período, foi observado se há o crescimento típico de coliforme total sendo caracterizado por ter uma cor vermelho púrpura, com $0,5 \mathrm{~mm}$ ou mais de diâmetro, rodeadas com halo avermelhado de precipitação de sais biliares. As colônias típicas e também atípicas quando presentes, foram contadas e após, foram determinados o número de UFC/g multiplicando o número de colônias encontradas pelo inverso da diluição.

Para a confirmação de coliformes totais, colônias típicas e atípicas de cada 
placa foram inoculadas em tubos contendo $9 \mathrm{~mL}$ de meio Caldo Verde Brilhante Bile $2 \%$ Lactose contendo tubo de Durhan invertido. Os tubos foram incubados por 24-48 horas a $35^{\circ} \mathrm{C} \pm 2^{\circ} \mathrm{C}$ e após esse período foi verificada a presença de turbidez do meio com formação de gás sendo este 0 resultado positivo confirmativo para coliformes totais.

A verificação da presença de coliformes termotolerantes foi realizada através da repicagem dos tubos positivos de Caldo Verde Brilhante Bile 2\% Lactose para tubos com o meio Caldo Escherichia coli, contendo tubo de Durhan invertido. Depois de homogeneizados, os tubos foram incubados em banho-maria a $45^{\circ} \mathrm{C}$ durante 24 horas. A turvação e formação de gás nos tubos de Durhan confirma a presença de coliformes de origem fecal.

\section{RESULTADOS E DISCUSSÃO}

Os resultados das análises microbiológicas estão demonstrados na Tabela 1.

Tabela 1 - Qualidade microbiológica de salada de frutas.

\begin{tabular}{ccccc}
\hline Amostra & UFC/g & Coliforme total & Coliforme termotolerante \\
\hline A & 30 & + & - \\
B & 1.900 & + & - \\
C & 150 & + & - \\
D & 0 & - & - \\
E & 20 & + & - \\
F & 60 & + & - \\
G & 0 & - & - \\
H & 50 & - & - \\
I & 190 & + & - \\
J & 1.200 & + & - \\
K & 20 & + & - \\
L & 10 & + & - \\
M & 23.000 & + & - \\
N & 30 & + & - \\
R & 10 & + & - \\
S & 20 & + & - \\
T & 20 & + & - \\
U & 0 & - & - \\
V & 0 & - & - \\
X & 70 & + & \\
\hline
\end{tabular}

(+) presença, (-) ausência.

Embora, todas as amostras apresentaram um resultado negativo para a presença de coliformes termotolerantes, $75 \%$ delas tiveram a presença de coliformes totais confirmada, e mesmo que sua contagem não é exigida pela legislação sanitária, como esses microrganismos comumente são contaminantes ambientais, sua contagem elevada sugere uma deficiência na 
qualidade higiênico sanitária do alimento (BRANT et al., 2012), que pode ser ocasionada por falhas no treinamento do manipulador de alimentos e por um conhecimento insuficiente das exigências da legislação, resultando em diversos erros na produção e distribuição do produto (RODRIGUES et al., 2017).

Resultados similares foram encontrados por Pinheiro e colaboradores (2011), que ao analisar sete amostras de saladas de frutas, provenientes de quiosques, comercializadas em um shopping de Fortaleza - CE, constatou que todas as amostras estavam dentro dos padrões legais vigentes para coliformes termotolerantes.

Nos estudos de Smanioto et al. (2009), ao analisar 30 amostras de frutas e hortaliças minimamente processadas procedentes de supermercados da cidade de Bauru - SP e região, verificou que todas as amostras de frutas analisadas se encontravam de acordo com as exigências da legislação vigente, sendo que algumas amostras apresentaram contagens de coliformes totais igual ou maior que 1.100 $\mathrm{NMP} / \mathrm{g}$.

Coliformes totais são bactérias gramnegativas, anaeróbias, facultativas, em forma de bastonetes, com a capacidade de fermentar a lactose com produção de ácido e gás, em um período de $48 \mathrm{~h}$, a $35^{\circ} \mathrm{C}$. Sua presença no alimento indica que houve algum erro nas condições de higiene durante a preparação, não indicando absolutamente a existência de contaminação de origem fecal, uma vez que esses microrganismos também podem ser encontrados em outros ambientes (FORSYTHE, 2013). Porém, esses microrganismos podem reduzir a vida útil do produto e oferecer riscos à saúde do consumidor (SILVA et al., 2014)

A presença de coliformes totais nas saladas de frutas pode ser explicada, dentre outros fatores, pela qualidade da água empregada no preparo (JAY, 2005). Uma vez que é utilizada tanto na higienização das frutas, como na etapa de lavagem e desinfecção, processos que se constituem como pontos críticos para a higiene dos alimentos (GERMANO; GERMANO, 2011). O uso de uma água de boa qualidade, uma higiene regular das caixas d'agua, além de um processo correto de higienização e sanitização das frutas, podem contribuir para a segurança desse alimento (BERBARI et al., 2001).

Segundo Silva e colaboradores (2016), outros fatores como o uso de uma matéria prima de má qualidade ou erros cometidos durante 0 processo de manipulação do alimento tais como uma higienização inadequada dos utensílios utilizados, das bancadas e das mãos dos manipuladores podem contribuir para uma contaminação por coliformes totais. Millezi e colaboradores (2007), ao avaliar a qualidade microbiológica das mãos de 22 manipuladores na indústria de alimentos, obteve como resultado que $9,1 \%$ das 
amostras estavam contaminadas por coliformes termotolerantes e $45,5 \%$ por coliformes totais.

Portanto, faz-se necessário a adesão das Boas Práticas de Fabricação, em conformidade com a RDC 216/2004 (BRASIL, 2004) com o propósito de prevenção e controle de riscos de contaminação. Um processo de educação nutricional direcionado para uma manipulação adequada dos alimentos pode contribuir para aumentar a segurança do manipulador no preparo dos alimentos, uma fiscalização mais acentuada pelas autoridades competentes também se faz essencial, para o fornecimento de um alimento seguro do ponto de vista microbiológico (SOUZA, 2006).

\section{CONCLUSÃO}

Os resultados apontaram ausência de coliformes termotolerante em todas as amostras, isso é um indicativo que o produto pode não ter sofrido uma contaminação de origem fecal.

O índice de coliformes totais é utilizado como indicador das condições higiênicas do ambiente onde o alimento foi preparado e dos manipuladores que prepararam esse alimento e mesmo sua contagem não sendo exigida pela legislação, sua presença em grande parte das amostras, indica que esse alimento foi preparado de forma inadequada.
A preparação desse alimento de acordo com as boas práticas de fabricação, o uso de uma água de boa qualidade, além de uma higienização das superfícies e das mãos dos manipuladores de maneira correta, pode contribuir para a segurança microbiológica desse alimento.

\section{REFERÊNCIAS BIBLIOGRÁFICAS}

AMERICAN PUBLIC HEALTH ASSOCIATION (APHA). Committe on Microbiologycal Methods for Foods. Compendiun of Methods for the Microbiologycal Examination of Foods. Washington: APHA, 2015.

BERBARI, S. A. G.; PASCHOALINO, J. E.; SILVEIRA, N. F. A. Efeito do cloro na água de lavagem para desinfecção de alface minimamente processada. Ciênc. Tecnol. Aliment, Campinas , v.21, n.2, 2001

BRANT, L. M. F.; FONSECA, L. M.; SILVA, M. C. C. Avaliação da qualidade microbiológica do queijo-de-minas artesanal do Serro-MG. Revista Brasileira de Produtos Agroindustriais, Campina Grande, v.14, n.2, p.125-130, 2012.

BRASIL. Ministério da Saúde. ANVISA Agência Nacional de Vigilância Sanitária. Regulamento técnico sobre padrões microbiológicos para alimentos RDC № 12 . Diário Oficial da União; Poder Executivo, janeiro de 2001. 
BRASIL, Ministério da Saúde. Resolução RDC nํ 216, de 15 de setembro de 2004. Regulamento Técnico de Boas Práticas para Serviços de Alimentação. Disponível em http://portal.anvisa.gov.br. Acesso em 14 out 2019.

FORSYTHE, S. J. Microbiologia da segurança dos alimentos. 2 ed, Porto Alegre: Artmed,2013.

GERMANO, P. M. L.; GERMANO, M. S. Higiene e vigilância sanitária de alimentos. 4 ed, Barueri: Manole,2011.

JAY, J. M. Microbiologia de Alimentos. $6^{\underline{a}}$ ed. Porto Alegre: Artmed, 2005. 711 p.

JEDDI, M. Z.; YUNESIAN, M.; GORJI, M. E.; NOORI, N.; POURMAND, M. R.; KHANIKI, G. R. J. Microbial Evaluation of Fresh, Minimally-processed Vegetables and Bagged Sprouts from Chain Supermarkets. J Health Popul Nutr, v.32, n.3, p.391-399, 2014.

MAISTRO, L.C., MIYA, N.T., SANT'ANA, A.S., PEREIRA, J.L. Microbiological quality and safety of minimally processed vegetables marketed in Campinas, SP e Brazil, as assessed by traditional and alternative methods. Food Control, v.28, p.258-264, 2012.
MILLEZI, A. F.; TONIAL, T. M.; ZANELLA, J. P.; MOSCHEN, E. E. S.; ÁVILA, C. A. C.; KAISER, V. L.; HOFFMEISTER, S. Avaliação e qualidade microbiológica das mãos de manipuladores e do agente sanificante na indústria de alimentos. Analytica, n. 28, p. 74-79, 2007.

OLIVEIRA, E. N. A. D.; SANTOS, D. D. C. Tecnologia e processamento de frutos e hortaliças. Natal: IFRN, 2015. 240 p.

PINHEIRO, A. M.; ABREU, C. R. A.; MAIA, G. A.; SOUSA, P.; FIGUEIREDO, E. A.T.; ROCHA, E. M. F. F.; COSTA, J. M. C. Avaliação das características de qualidade, componentes bioativos e qualidade microbiológica de salada de frutas tropicais. Alim. Nutr, v.22, n.3, p.435-44, 2011.

RODRIGUES, A. C. S.; ROCHA, P. S. G.; SOARES, L. S. Perfil microbiológico de alimentos e bebidas servidas em lanchonetes e restaurantes localizados em instituição de ensino de salvador, BA. Higiene alimentar, v.31, n.274/275, p.6670, 2017.

SANTOS, T. B. A.; SILVA, N.; JUNQUEIRA, V. C. A.; PEREIRA, J. L. Microrganismos indicadores em frutas $\mathrm{e}$ hortaliças minimamente processadas. Brazilian Journal of Food Technology, Campinas, v.13, n.2, p.141-146, 2010. 
SILVA, G. C. CHAGAS, T, SOARES, L. S. Qualidade de polpas de frutas congeladas comercializadas na cidade de salvador BA. Higiene Alimentar, v. 30, n. 258, p.7882, ago.2016.

SILVA, J. A. R.S.; GONÇALVES, J. T. T.; MIRANDA, A. S.; BRITO, M. S.; SANTANA, R. F. Análise microbiológica de saladas de frutas comercializadas na região central de vitória da conquista. C\&D-Revista Eletrônica da FAINOR, Vitória da Conquista, v. 11, n. 3, p. 633-642, 2018.

SILVA, W, F.; NASCIMENTO, T. B.; OLIVEIRA, L. F; FERNANDES, N. D. S. F.; OLIVEIRA, P. M. C.; Análise de coliformes totais e termotolerantes em vegetais minimamente processados comercializados em um supermercado de Montes Claros, Minas Gerais. Nutrivisa, Fortaleza, v.1, n. 3, 2014.

SMANIOTO, T,F.; PIROLO, N, J.; SIMIONATO, E, M,R,S.; ARRUDA, M,C. Qualidade microbiológica de frutas e hortaliças minimamente processadas. Rev Inst Adolfo Lutz, São Paulo, v.68, n.1, 2009.

SOUZA, C. P. D. Segurança alimentar e doenças veiculadas por alimentos: utilização do grupo coliforme como um dos indicadores de qualidade de alimentos. Revista APS, Juiz de Fora, v. 9, n.1, p. 8388, 2006. 